11. Сериков Ю.Б. Исследование грота на камне Дождевом (р. Чусовая) // Вопросы археологии Урала. Вып. 21. Екатеринбург: УрГУ, 1993. С. 120-143.

12. Никитин В.В. Каменный век Марийского края. Йошкар-Ола: МарНИИ, 1996. 177 с.

13. Буров Г.М. Искусство Крайнего Северо-Востока Европы в эпоху неолита - раннего металла и его семантика // Наскальные рисунки Евразии. Новосибирск: Наука, 1992. С. 14-28.

14. Викторова В.Д. Культовые озерные памятники // Культовые памятники горно-лесного Урала. Екатеринбург: УрО РАН, 2004. С. 144-157.

15. Викторова В.Д., Чаиркина Н.М., Широков В.Н. Гора и водоплавающая птица в мировидении древнего уральского населения // Уральский исторический вестник. 1997. № 4. С. 40-64.

16. Чаиркина Н.М. Глиняные тарелки со стилизованными орнитоморфными изображениями из VI разреза Горбуновского торфяника // Археология, этнография и антропология Евразии. 2013. № 3 (55). С. 68-80.

17. Викторова В.Д. Коптяковская культура в горно-лесном Зауралье // III Берсовские чтения: к 95-летию А.А. Берса и 90-летию Е.М. Берс: мат-лы науч.практ. конф. Сентябрь 1997 г., г. Екатеринбург / отв. ред. Н.Л. Кривоносова. Екатеринбург: Банк культурной информации, 1999. С. 49-54.

18. Эдинг Д.Н. Резная скульптура Урала // Труды Государственного исторического музея. Вып. Х. М., 1940. $104 \mathrm{c}$.
19. Мошинская В.И. О зауральских зооморфных изображениях, связанных с глиняной посудой (К вопросу о древних контактах в уральской среде) // Проблемы археологии и древней истории угров. М.: Наука, 1972. С. 56-65.

20. Усачева И.В. К истокам мировоззрения древних уральцев (по материалам мелкой глиняной и кремневой пластики эпохи неолита - бронзы оз. Андреевского Тюменской обл.) // Вопросы археологии Урала. Вып. 23. Екатеринбург: Изд-во УрГУ, 1998. C. $105-134$.

21. Викторова В.Д., Колмакова В.В., Федорова А.Ю. И разные народы побывали здесь... // Образы и сакральное пространство древних эпох. Екатеринбург: Аква-Пресс, 2003. С. 9-20.

22. Ковалева В.Т. Образ мира населения аятской культуры (по орнаментам на сосудах) // Четвертые Берсовские чтения. Екатеринбург: Аква-Пресс, 2004. C. $76-82$.

23. Ковалева В.Т., З Зырянова С.Ю. О семантике обряда у камня Дыроватого и образа водоплавающей птицы на энеолитической посуде в Зауралье // Проблемы археологии: Урал и Западная Сибирь (к 70летию Т.М. Потемкиной). Курган: Изд-во Курганского гос. ун-та, 2007. С. 50-55.

24. Молодин В.И., Чемякина М.А. Орнитоморфные навершия одиновской культуры (Западносибирская лесостепь) // Уральский исторический вестник. 2010. № 1. C. 5-14.

\title{
THE WATERFOWL IMAGE IN THE ART OF THE NEO-ENEOLITHIC POPULATION OF THE URALS
} (C) 2019

Serikov Yuri Borisovich, doctor of historical sciences, leading researcher of Archaeological Laboratory Nizhny Tagil State Social and Pedagogical Institute (branch) of Russian State Vocational Pedagogical University (Nizhny Tagil, Sverdlovsk Region, Russian Federation)

Abstract. The first generalizing work on waterfowl images in Neolithic art was presented by N.N. Gurina in 1972. Based on numerous findings the author defines their chronology and distribution area, characterizes the features of images and offers reconstruction of the overall picture of the world. At the same time Ural is the easternmost distribution area of waterfowl images marked by only a few finds. Nowadays the situation presented by N.N. Gurina has changed a lot. On the territory of Ural dozens of Neolithic and Eneolithic sculptural images of waterfowls made of stone, clay, bone, horn and wood were discovered. Even more known are the engraved images of birds on ceramic vessels. Practically all those vessels belong to the Eneolithic time. According to the Ural archeologists the image of the bird appeared in different symbolic meanings: the bird was considered to be the main character in the creation of the world; it could have been demiurge, ancestor and progenitor of the genus; the bird is associated with the development of craft cult; it could reflect the calendar symbols. The assumption of N.N. Gurina that the area of distribution of waterfowl images coincides with the area of residence of the population of the Finno-Ugric language group is confirmed.

Keywords: Ural; waterfowl; duck; goose; swan; loon; marsh hen; Neolithic; Eneolithic; sculptural images of stone, horn and clay; flint sculpture; engraved images; graphic images of birds on vessels; semantics of image of a bird; myth of diving duck; comparative analysis.

УДК 902.01

DOI 10.24411/2309-4370-2019-12217

Статья поступила в редакцию 25.01.2019

\section{АКТУАЛЬНЫЕ ВОПРОСЫ В ИЗУЧЕНИИ РАННЕГО ЭНЕОЛИТА ДОНСКОЙ ЛЕСОСТЕПИ (ХРОНОЛОГИЯ, ПЕРИОДИЗАЦИЯ, СИНХРОНИЗАЦИЯ)}

(C) 2019

Скоробогатов Андрей Михайлович, кандидат исторических наук, начальник археологического отдела ООО «Терра» (г. Воронеж, Российская Федерация)

Аннотащия. Долгое время энеолит Донской лесостепи оставался одной из самых малоизученных эпох в археологической схеме региона. Однако с конца 1960-х годов памятники с материалами эпохи энеолита активно исследуются на территории Воронежской и Липецкой областей. К 1980-м годам у исследователей сложилась концепция развития культур медно-каменного века в рамках мариупольской культурно-исторической области Днепро-Доно-Уральского междуречья, актуальная и в настоящее время. Были обоснованы 
критерии для выделения эпохи энеолита на степных и лесостепных пространствах Восточно-Европейской степи и лесостепи. Обозначалась идея их синхронизации с комплексами периода Триполья А. Ранний энеолит в Донской лесостепи маркировался появлением населения с воротничковой керамикой нижнедонской культуры. Вопросы хронологии раннего энеолита решались исключительно методами аналогий с материалами соседних территорий и синхронизацией с местными неолитическими комплексами. В данной работе рассматриваются проблемы хронологии, периодизации и синхронизации материалов эпохи раннего энеолита территории Донской лесостепи. Основное внимание уделяется вопросам абсолютного датирования нижнедонской культуры мариупольской культурно-исторической области и вариантах ее синхронизации с ранним Трипольем. По всем имеющимся к настоящему времени данным, ранний энеолита региона можно датировать от 5300 до 4250 лет до н.э.

Ключевые слова: Донская лесостепь; Средний Дон; Верхний Дон; Воронежская область; Липецкая область; ранний энеолит; мариупольская культурно-историческая область; нижнедонская культура; керамика; медь; грунтовые могильники; погребения; раннее Триполье; радиоуглеродные даты; синхронизация; периодизация; хронология.

Выделение среди керамических комплексов энеолитических материалов для памятников Донской лесостепи началось лишь во второй половине 1960-х гг. [1-4], однако благодаря интенсивным полевым работам, в основном в зоне Воронежского водохранилища, уже к началу 1970-х гг. было обосновано наличие нескольких культур медно-каменного века, занявших свое место в хронологической схеме между неолитом и эпохой бронзы. Начало эпохи энеолита маркировалось появлением на памятниках региона населения с особой «воротничковой» керамикой, отличающейся от местной неолитической, с аналогиями в материалах стоянок у станицы Цимлянской и верхних слоев поселения Ракушечный Яр [5]. При крайне ограниченном количестве введенных в научный оборот синхронных комплексов к югу от территории Донской лесостепи, «материалы нижнедонского типа» [5, с. 19] со временем переросли в культуру раннего энеолита, получившей название «нижнедонской» [6], заняв место в круге культур мариупольской культурно-исторической области (далее МКИО) раннего энеолита [7].

К середине 1980-х гг. И.Б. Васильевым и А.Т. Синюком были охарактеризованы основные признаки культур степи-лесостепи Днепро-Доно-Уральского междуречья, по которым их можно было относить к раннему энеолиту [7, с. 30-31]. Признаки эти (от воротничковой керамики до украшений из золота и чистой меди балканского происхождения) - неравнозначны и не равно встречаемы даже для соседних памятников одной культуры и в основном (за исключением керамики) распространены в материалах «закрытых» погребальных комплексов - могильниках мариупольского типа. В итоге получается, что для поселенческих материалов самым приемлемым признаком остается один единственный - воротничковая керамика, т.к. памятников неолита - энеолита с надежной стратиграфией - единицы из десятков исследованных. Однако применять такой подход, основанный исключительно на типологии и морфологии при недостаточной осведомленности в имеющейся проблематике, надо осторожно. Иначе появляются «энеолитические» постройки с керамикой аким-сергеевского типа на р. Цна севернее Тамбова [8] либо «энеолитический» клад медных изделий в Похоперье [9].

Как заметил В.В. Ставицкий, различные исследователи по-разному понимают начало энеолитической эпохи, но все без исключения отмечают роль нового материала - меди. Разница лишь в том, что считать за основу начала эпохи палеометалла - первое появ- ление металлических изделий как таковых либо различные варианты способов его обработки и масштабность распространения и внедрения в производственную сферу [10, с. 256-257]. В этом плане А.Т. Синюк в одной из работ, в целом озвучивая собственное видение начала энеолитической эпохи, заметил, что для территории лесостепи Днепро-ДоноВолжского междуречья металлургический показатель неактуален ввиду исключительной редкости медных изделий как археологического источника, а также высказался об абсолютизации металлургического признака в археологической периодизации [11, c. 14-17].

Можно сказать, что идея объединения культур с воротничковой керамикой (и иными признаками) в рамках МКИО раннего энеолита Днепро-ДоноВолжского междуречья прошла проверку временем и до сих пор является основным ведущим подходом в концепции развития археологических культур неолита - начала эпохи палеометалла региона.

Тем не менее ряд моментов в археологии позднего неолита - раннего энеолита Донской лесостепи требует своего объяснения, и проблемы, назревшие еще в 1980-е гг., ждут своего решения. В разной степени актуальности это вопросы хронологии, периодизации, синхронизации, хозяйства, уровня межкультурного взаимодействия автохтонного и пришлого населения региона в процессе смены эпох и ряд других. В данной работе более подробно рассмотрим проблемы хронологии, периодизации и синхронизации периода перехода от неолита к энеолиту.

Еще И.Б. Васильев в 1980-е гг. предложил синхронизировать культуры мариупольской КИО степилесостепи с ранним Трипольем, взяв за основу идею Д.Я. Телегина о синхронизации II этапа днепродонецкой культуры (а соответственно и мариупольских памятников) с Трипольем А [12, с. 62]. При почти полном отсутствии абсолютных дат и редких «закрытых» комплексов раннего степного-лесостепного энеолита такая позиция выглядела вполне оправданной.

В период с 1990-х гг. до начала XXI в. культуры мариупольской КИО датировали, как правило, от конца V по первую половину IV тыс. до н.э. по некалиброванной хронологии. Азово-днепровскую, нижнедонскую, самарскую и прикаспийскую культуры исследователи синхронизировали с ранним Трипольем [13-15]. Однако с начала двухтысячных годов появляются опубликованные результаты абсолютного 
датирования материалов, происходящих как с памятников неолита и энеолита, в основном ДнепроДонского междуречья, так и комплексов общности Кукутень-Триполье. Эти данные дали основания для пересмотра абсолютных датировок материалов неолита и энеолита обширного региона Восточно-Европейской степи и лесостепи и их удревнении [16-18].

Такие тенденции в хронологии позднего неолита - раннего энеолита Восточно-Европейской степилесостепи со временем были отражены и для раннего энеолита Донской лесостепи [19, с. 273]. Имеющиеся материалы позволили нам начало энеолитического периода региона датировать приблизительно концом третьей четверти VI тыс. до н.э. в калиброванных значениях (CalBC), взяв за основу хронологические разработки Н.С. Котовой $[20$, с. $21 ; 19$, с. 273]. Что немаловажно, абсолютные даты из верхних слоев поселения Ракушечный Яр (с пятого слоя) указывают на их синхронность с ранним энеолитом Донской лесостепи [21, с. 230-231]. Здесь отметим, что это по большей части касается слоя 5 , т.к. многие даты слоев 4-2 Ракушечного Яра выглядят некорректными в контексте общей хроностратиграфии поселения.

Нижнедонская культура на территории Донской лесостепи была нами синхронизирована с заключительной стадией этапа 16 первого периода и вторым периодом азово-днепровской культуры, а также прикаспийской культурой Нижнего Поволжья и Самарской культурой Среднего Поволжья по наличию в комплексах этих культур общестадиальных признаков. Среди них, помимо керамики с воротничковым украшением венчиков и прочерченно-гребенчатой орнаментацией, четко атрибутируются пластинки мариупольского типа из клыков кабана и зооморфные костяные изделия.

Благодаря полевым исследованиям последних лет на юге Среднего Подонья (стоянка Черкасская, грунтовое погребение у хутора Голубая Криница) были получены материалы, позволившие начало эпохи энеолита в Донской лесостепи синхронизировать со временем функционирования могильников мариупольского типа к западу и востоку от Дона (Никольский, Ясиноватский и Лысогорский, части Дереивского и Мариупольского могильников в Приазовье и Поднепровье, а также Съезженский в Среднем Поволжье [22, с. 12-13].

Дальнейшие исследования на границе степной и лесостепной зон в Воронежской области показали наличие не одиночного погребения у хут. Голубая Криница, а небольшого грунтового могильника [23; 24]. Особенности погребального обряда (вытянутые на спине одиночные и коллективные погребения с преимущественно южной ориентировкой) и наличие яркого инвентаря (морские раковины, раковины Unio, изделия из их створок, пластинки-нашивки с эмалью из клыков кабана, зубов бобра и сурка, кремневые наконечники и ножи, костяные орудия, керамика, медное изделие) доказывают раннеэнеолитическую принадлежность грунтового могильника.

Итак, в настоящее время все больше фактов позволяют начало раннего энеолита на Среднем Дону синхронизировать с Трипольем А. Однако нельзя не сказать о существовании проблемы хронологии внутри самих культур круга Кукутени-Триполье. Так, Ю.Я. Рассамакин акцентирует внимание на тен- денции удревнения раннетрипольских комплексов территории современной Украины [25]. Даты, которые были получены исключительно в Киевской лаборатории (по костям животных) по материалам раннетрипольских поселений Украины, охватывают период приблизительно от 5450 до $4700 \mathrm{CalBC}$ [26, c. 439]. Даты, полученные в Берлинской лаборатории по углю и костям животных, моложе, даже по комплексам с одного памятника, на 600-800 радиоуглеродных лет, и начинаются приблизительно от $4800 \mathrm{CalBC}$ [25, p. 21-24]. О наличии двух хронологий для Триполья А пишут И.В. Палагута и Е.Г. Старкова: более ранней и длительной, от 5400 до 4700-4600 CalBC, и более поздней и короткой, 5050-4600 или 4800-4300 $\mathrm{CalBC}$, с более приемлемым авторами узким (т.е. более поздним) вариантом датировок [27, с. 100].

Абсолютные даты (см. табл. 1, рис. 1) для раннего энеолита Донской лесостепи начали появляться совсем недавно [28, с. $252 ; 29$, с. $238 ; 19$, с. 273]. Первоначально все они без исключения были сделаны по образцам керамики в Киевской лаборатории (табл. 1, образцы №№ 1-5; рис. 1: 1, 2, 5). Затем к ним добавились две даты по одному воротничковому фрагменту (рис. 1: 3), сделанные по внешнему нагару и внутренней органике из черепка [30, с. 174], а также одна дата (рис. 1: 4), сделанная по нагару с керамики черкасского типа [31, с. 246], выполненные в Хельсинкской лаборатории (AMS датирование).

Вызывает интерес разница в датировках, выполненных по одному образцу с Черкасской-3 стоянки. Авторы публикации этих образцов считают, что дата, полученная по нагару, удревнена ввиду наличия резервуарного эффекта, и валидной считают более позднее значение по керамике [30, с. 173]. И если мы не будем брать в расчет самые ранние и самые поздние имеющиеся даты (образцы №o 4-6), то у нас и получится тот хронологический отрезок времени, который характерен для более поздней хронологии Триполья А, о котором писал Ю.Я. Рассамакин [25]. Однако до получения дополнительных датировок по разным материалам с территории Донской лесостепи, а также четких и надежных стратиграфических данных будем считать эту проблему открытой. Дата по керамике с Курино-1 значительно моложе остальных абсолютных значений, и если она валидна, то может маркировать финал воротничковой традиции для территории Верхнего Дона. На Среднем Дону, вероятно, воротничковая традиция (керамика нижнедонской культуры и керамика черкасского типа) исчезает несколько ранее, с распространением здесь населения поздней среднестоговской (дереивской) культуры.

Для четкой синхронизации нижнедонской культуры с местной среднедонской неолитической культурой к настоящему моменту не так уж и много данных. В нашем распоряжении имеется только синкретическая керамика черкасского типа, по которой получена всего одна абсолютная дата (табл. 1, № 8). К сожалению, на поселенческих памятниках Донской лесостепи нет четких «чистых» слоев с материалами нижнедонской культуры либо керамикой черкасского типа. Тем не менее имеющиеся данные позволили нам начало второго этапа среднедонской неолитической культуры сопоставить с появлением раннеэнеолитического населения [31, с. 246]. 
Таблица 1 - Радиоуглеродные даты раннего энеолита Донской лесостепи

\begin{tabular}{|c|c|c|c|c|c|c|c|}
\hline № & $14 \mathrm{C} \mathrm{(BР)}$ & $\begin{array}{c}\text { Калиброванная } \\
\text { дата }(2 \sigma) \\
(\mathrm{CalBC})\end{array}$ & $\begin{array}{c}\text { Лабораторный } \\
\text { индекс }\end{array}$ & Материал & $\delta 13 \mathrm{C}$ & Памятник & Публикация \\
\hline 1 & $5930 \pm 90$ & $5040-4580$ & $\mathrm{Ki}-16641$ & Керамика & - & Черкасская стоянка & {$[19]$} \\
\hline 2 & $5710 \pm 90$ & $4730-4350$ & $\mathrm{Ki}-16642$ & Керамика & - & Черкасская стоянка & {$[19]$} \\
\hline 3 & $5920 \pm 90$ & $5030-4540$ & $\mathrm{Ki}-13327$ & Керамика & - & Ксизово-6 & {$[28]$} \\
\hline 4 & $5170 \pm 100$ & $4250-3700$ & $\mathrm{Ki}-16393$ & Керамика & - & Курино-1 & {$[28]$} \\
\hline 5 & $6170 \pm 80$ & $5310-4900$ & $\mathrm{Ki}-16648$ & Керамика & - & Карамышево 19 & {$[29]$} \\
\hline 6 & $6169 \pm 26$ & $5215-5040$ & $\mathrm{Hela}-3734$ & Нагар & $-30,0$ & Черкасская-3 стоянка & {$[30]$} \\
\hline 7 & $5775 \pm 25$ & $4710-4540$ & $\mathrm{Hela}-3735$ & Керамика & $-28,2$ & Черкасская-3 стоянка & {$[30]$} \\
\hline 8 & $5763 \pm 32$ & $4710-4535$ & $\mathrm{Hela}-3884$ & Нагар & $-30,3$ & Черкасская стоянка & {$[31]$} \\
\hline
\end{tabular}
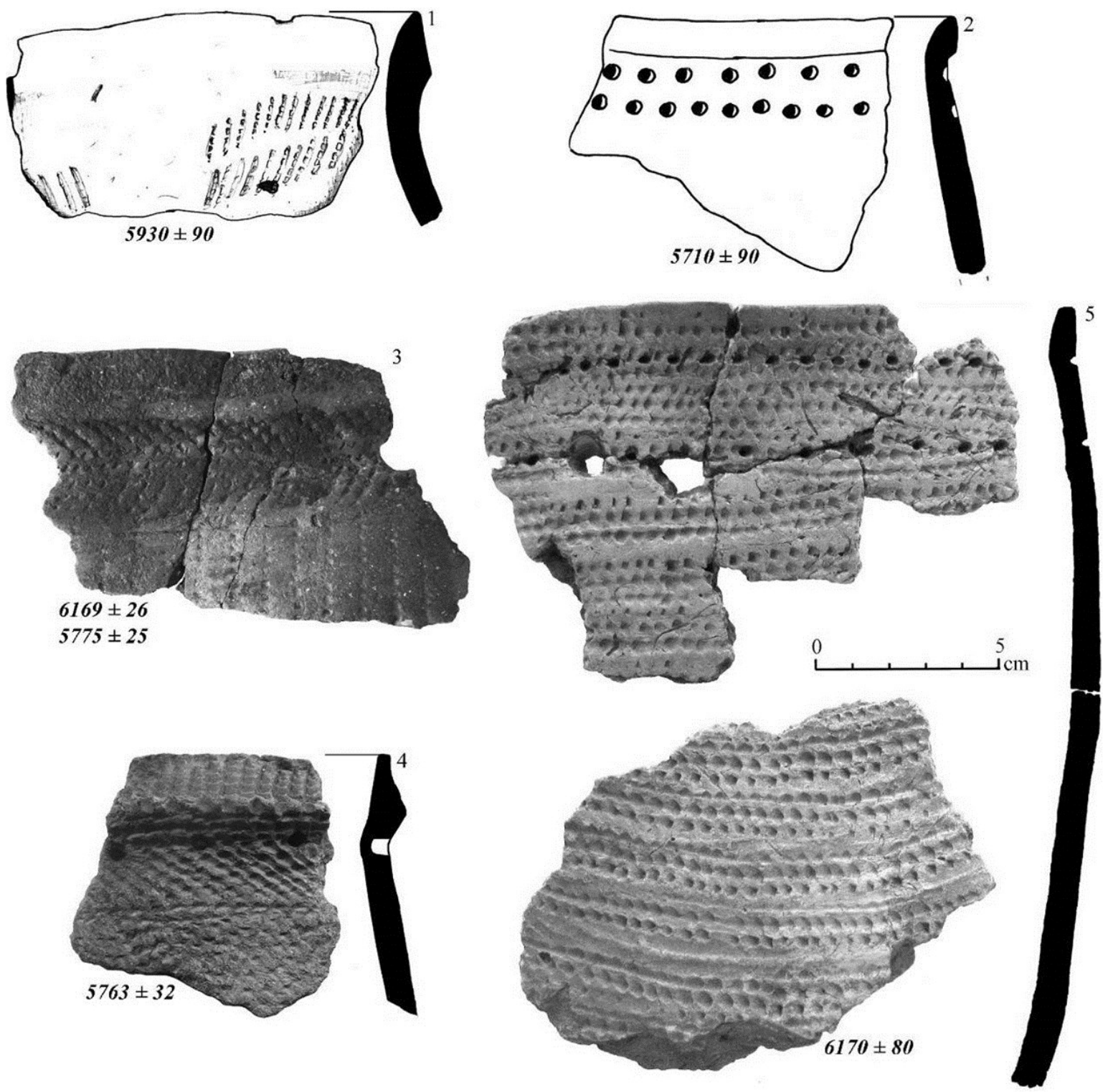

Рисунок 1 - Образцы продатированной керамики (даты С14 ВР).

1, 2, 4- стоянка Черкасская; 3- стоянка Черкасская-3; 5- поселение Карамышево 19 (по: [29])

Что касается выделения периодов внутри нижнедонской культуры, то пока для этого у нас также нет надежных (прежде всего стратиграфических) данных, хотя определенные наработки для этого имеются [32, с. 205].

Таким образом, несмотря на малое количество абсолютных датировок, к настоящему времени ранний энеолит Донской лесостепи относится к периоду от 5300 до 4250 CalBC. В то же время, если не брать в расчет самые ранние и поздние С-14 значения (табл. 1, образцы №o 4-6), то временной диапазон значительно сузится - буквально от 5040 до 4500 CalBC $(2 \sigma)$, что соответствует более «короткой» и более «поздней» хронологии раннего Триполья.

\section{Список литературы:}

1. Синюк А.Т. Поселение эпохи неолита у станции Отрожка // Из истории Воронежского края. Воронеж: Издательство Воронежского университета, 1966. C. $107-114$. 
2. Синюк А.Т. Новые материалы к изучению неолита в Среднем Подонье // Сборник научных студенческих работ. Вып. I (гуманитарные науки). Воронеж: Изд-во Воронежского университета, 1968. C. $27-33$.

3. Пряхин А.Д., Синюк А.Т. Древности из зоны Воронежского моря. Воронеж: Центрально-Черноземное книжное издательство, 1968. $32 \mathrm{c}$.

4. Левенок В.П. Исследования в зоне Липецкого моря // Археологические открытия 1967 года. М.: Наука, 1968. С. 32-34.

5. Синюк А.Т. Памятники неолита и энеолита на Среднем Дону: автореф. дис. ... канд. ист. наук. М., 1971. $22 \mathrm{c}$.

6. Синюк А.Т. Энеолит лесостепного Дона // Энеолит Восточной Европы. Куйбышев: Издательство КГПИ им. В.В. Куйбышева, 1980. С. 53-72.

7. Васильев И.Б., Синюк А.Т. Энеолит восточноевропейской лесостепи. Куйбышев: Издательство КГПИ им. В.В. Куйбышева, 1985. 118 с.

8. Андреев С.И. Энеолитические постройки поселения Коровий Брод // Археологические памятники Восточной Европы: межвуз. сб. науч. тр. Вып. 12. Воронеж: ВГПУ, 2006. С. 66-74.

9. Хреков А.А., Быков В.Ю. Новые материалы раннего энеолита лесостепного Прихоперья: Завьяловский клад (предварительная публикация) // Археологическое наследия Саратовского края. Вып. 10. Саратов: Изд-во «Научная книга», 2012. С. 6-14.

10. Ставицкий В.В. Периодизация энеолита Восточной Европы // Археологические памятник Восточной Европы: межвуз. сб. науч. тр. Вып. 13. Воронеж: ВГПУ, 2009. С. 256-258.

11. Синюк А.Т. О понятии «энеолит» для лесостепи Днепро-Доно-Волжского междуречья // Исследование памятников археологии Восточной Европы. Воронеж: Издательство ВГПИ, 1988. С. 13-23.

12. Васильев И.Б. Энеолит Поволжья (степь и лесостепь). Куйбышев: Издательство КГПИ им. В.В. Куйбышева, 1981. 129 с.

13. Котова Н.С. Мариупольская культурно-историческая область (Днепро-Донское междуречье) // Археологічні памятки та істория стародавнього населення Украіни. Вип. 1. Луцьк: Издательство Вежа, 1994. 167 c.

14. Гурин Ю.Г. Памятники раннего энеолита бассейна Северского Донца. Луганск: Издательство «Осирис», 1998. 160 с.

15. Юдин А.И. Варфоломеевская стоянка и неолит степного Поволжья. Саратов: Изд-во Сарат. унта, 2004. $200 \mathrm{c}$.

16. Черных Е.Н., Авилова Л.И., Орловская Л.Б. Металлургические провинции и радиоуглеродная хронология. М.: Изд-во ИА РАН, 2000. 95 с.

17. Котова Н.С. Неолитизация Украины. Луганск: Шлях, 2002. 267 с.

18. Телегин Д.Я. О хронологии и периодизации культур неолита и медного века Юго-Запада Восточной Европы. Понятие о нео-энеолитическом времени региона // Проблемы хронологии и этнокультурных взаимодействий в неолите Евразии (хронология неолита, особенности культур и неолитизация регионов, взаимодействия неолитических культур в Восточной и Средней Европе). СПб.: ИИМК РАН, 2004. С. 106-121.
19. Скоробогатов А.М. Энеолит бассейна Верхнего и Среднего Дона в свете новых данных // Тверской археологический сборник. 2013. Вып. 9. С. 264278.

20. Котова Н.С. Культурно-исторические процессы в Северном Причерноморье в VI-V тыс. до н.э.: автореф. дис. ... д-ра ист. наук. Киев, 2010. 28 с.

21. Цыбрий А.В., Ц Цыбрий В.В., Горелик А.Ф. «Затянувшаяся путина»: неолитическое рыболовство и собирательство на Нижнем Дону (по материалам исследований поселения Раздорская II) // Stratum Plus. 2016. № 2. C. 133-174.

22. Скоробогатов А.М. Энеолитические памятники Донской лесостепи: дис. ... канд. ист. наук. Воронеж, 2011. $22 \mathrm{c.}$

23. Скоробогатов А.М. Раскопки грунтового могильника мариупольского типа // Археологические исследования в Центральном Черноземье 2015. Липецк: Новый взгляд, 2016. С. 59.

24. Скоробогатов А.М. Исследования грунтового могильника мариупольского типа на юге Воронежской области // Археологические исследования в Центральном Черноземье 2016. Липецк - Воронеж: Новый взгляд, 2017. С. 70-71.

25. Rassamakin Y. Absolute Chronology of Ukrainian Tripolian Settlements // The Tripolye Culture GiantSettlements, in Ukraine. Formation, Development and Decline / eds. F. Menotti, A.G. Korvin-Piotrovskiy. Oxford and Oakville: Oxbow Books, 2012. P. 19-69.

26. Бурдо Н.Б. Новые данные для абсолютной датировки неолита и раннего энеолита на территории Украины // Stratum Plus. 2001-2002. № 2. С. 431-446.

27. Палагута И.В., Старкова Е.Г. Проблемы относительной хронологии Триполья-Кукутень и окружающих культур Балкано-Карпатского региона: радиокарбонные даты и археологические материалы // Принципы и методы датирования в археологии (неолит - средние века): коллективная монография / отв. ред. М.Т. Кашуба, Е. Кайзер. СПб.: ИИМК РАН, 2018. C. $97-123$.

28. Смольянинов Р.В., Свиридов А.А., Бессуднов А.Н. Материалы нижнедонской культуры на Верхнем Дону // Тверской археологический сборник. 2011. Вып. 8, т. І. С. 234-253.

29. Смольянинов Р.В. Поселение Карамышево 19 на Верхнем Дону // Тверской археологический сборник. 2013. Вып. 9. С. 232-248.

30. Андреев К.М., Барацков А.В., Выборнов А.А., Кулькова М.А., Ойнонен М., Посснерт Г., Медоуз Д., ван дер Плихт Й., Филиппсен Б. Новые радиоуглеродные даты неолитических и энеолитических памятников Поволжья и Подонья // Известия Самарского научного центра РАН. 2016. Т. 18, № 6. С. 170-177.

31. Скоробогатов А.М., Смольянинов Р.В., Сурков А.В., Ойнонен М., Посснерт Г. Хронология неолитических памятников лесостепного Подонья // $\mathrm{Pa}$ диоуглеродная хронология эпохи неолита Восточной Европы VII-III тысячелетия до н.э.: кол. моногр. / сост. Г.И. Зайцева, О.В. Лозовская, А.А. Выборнов, А.Н. Мазуркевич. Смоленск: Свиток, 2016. С. 244-260.

32. Скоробогатов А.М. Сравнительная характеристика керамики Мариупольской культурно-исторической области Верхнего и Среднего Дона // Верхнедонской археологический сборник. Вып. 6. Липецк: ЛГПУ, 2014. С. 203-208. 


\section{TOPICAL ISSUES IN THE STUDY OF THE EARLY AENEOLITHIC OF THE DON FOREST-STEPPE (CHRONOLOGY, PERIODIZATION, SYNCHRONIZATION)}

(C) 2019

Skorobogatov Andrey Mikhailovich, candidate of historical sciences, head of Archeological Department LLC «Terra» (Voronezh, Russian Federation)

Abstract. For a long time, the Eneolithic of the Don forest-steppe remained one of the least studied epochs in the archaeological scheme of the region. However, since the late 1960s, sites with materials of the Eneolithic have been actively explored on the territory of the Voronezh and Lipetsk Regions. By the 1980s, researchers had a concept for the development of copper-stone age cultures within the system of the Mariupol cultural-historical region of the Dnieper-Don-Ural interfluve, which is still relevant today. The criteria for distinguishing the Eneolithic era in the steppe and forest-steppe spaces of the East European steppe and forest-steppe were substantiated. The idea of their synchronization with complexes of the Tripolye A period was designated. The early Eneolithic in the Don foreststeppe was marked by the appearance of a population with specific ceramics of Nizhnedonskaya culture. Questions of the chronology of the early Eneolithic were solved exclusively by methods of analogies with the materials of neighboring territories and synchronization with the local Neolithic complexes. The paper deals with the problems of chronology, periodization and synchronization of materials from the early Aeneolithic of the territory of the Don forest-steppe. The focus is on the absolute dating of the Nizhnedonskaya culture of the Mariupol cultural-historical region and its synchronization with the early Tripolye Culture. According to all the data available to date, the region's early Eneolithic can be dated from 5300 to 4250 BC.

Keywords: Don forest-steppe; Middle Don; Upper Don; Voronezh Region; Lipetsk Region; early Eneolithic; Mariupol cultural-historical region; Nizhnedonskaya Culture; ceramics; copper; ground burial grounds; burials; early Tripolye Culture; radiocarbon dates; synchronization; periodization; chronology.

УДК $902.01,903$

DOI 10.24411/2309-4370-2019-12218

Статья поступила в редакцию 11.02.2019

\section{МАТЕРИАЛЫ РАННЕГО НЕОЛИТА СТОЯНКИ ЯРЛУКОВСКАЯ ПРОТОКА (ПУНКТ 222) НА ВЕРХНЕМ ДОНУ}

(C) 2019

Смольянинов Роман Викторович, кандидат исторических наук, заведующий кабинетом археологии и этнологии

Липеикий государственный педагогический университет имени П.П. Семенова-Тян-Шанского

(2. Липеик, Российская Федерация)

Куличков Алексей Александрович, заведующий отделом краеведческой работы Межпоселенческий координационно-методический иентр

Грязинского мунищипального района Липецикой области (2. Грязи, Липецฺкая область, Российская Федерация)

Юркина Елизавета Сергеевна, студент института истории, права и общественных наук

Липеикий государственный педагогический университет имени П.П. Семенова-Тян-Шанского

(2. Липецк, Российская Федерация)

Аннотация. В данной статье анализируются материалы расположенной в пойме реки Матыра (левый приток р. Воронеж) стоянки Ярлуковская протока (пункт 222) в Грязинском районе Липецкой области. Она исследовалась в 1963, 1964, 1967 и 1968 годах В.П. Левенком. Здесь были выявлены материалы трех ранненеолитических культур VI тыс. до н.э. Материалы елшанской культуры представлены венчиками и днищами от 12 сосудов. Почти вся посуда, кроме одного днища и нескольких стенок, без орнамента, за исключением одного или двух линий ямок. Вся керамика хорошо заглажена, для изготовления всех сосудов использовалась илистая глина. Условия расположения материалов в культурном слое подтверждают более раннее залегание керамики елшанской культуры. Керамика карамышевской культуры представлена фрагментами от трёх сосудов. Посуда преимущественно украшена мелкими овальными наколами, составленными в горизонтальные и косовертикальные ряды. Керамика лепилась из илистой глины. Посуда среднедонской культуры представлена венчиками и округлой формы днищами от 15 сосудов. Она украшена треугольными наколами или мелкими гребенчатыми отпечатками. Керамика лепилась из илистой глины. Изделия из камня представлены 304 единицами, преимущественно из кремня. Каменная индустрия может быть охарактеризована как отщеповопластинчатая. Памятник является в некоторой степени смешанным комплексом, поэтому чётких стратиграфических и планиграфических наблюдений залегания каменного инвентаря сделать не удалось.

Ключевые слова: Верхний Дон; лесостепь; ранний неолит; керамика; примесь; радиоуглеродное датирование; кремень; кварцит; среднедонская неолитическая культура; карамышевская неолитическая культура; елшанская неолитическая культура; накол; гребенчатый орнамент; орудие; отщеп; скребок; нож; многофункциональное орудие; пластина; нуклеус; типологический анализ.

Стоянка Ярлуковская Протока (пункт 222) (рис. 1: 1) была выявлена в 1963 г. В.П. Левенком в итоге исследований Верхне-Донской археологической экспе- диции Ленинградского отделения ИА АН СССР в ходе работ по сбору данных для археологической карты Липецкой области [1]. 